\title{
Chemical Modification of Lysine Residues in Bacillus licheniformis $\alpha$-Amylase: Conversion of an Endo- to an Exo-type Enzyme
}

\author{
Azadeh Ebrahim Habibi ${ }^{\dagger}$, Khosro Khajeh ${ }^{\star}$ and Mohsen Nemat-Gorgani ${ }^{\dagger, \beta, *}$ \\ 'Institute of Biochemistry and Biophysics, University of Tehran. P. O. Box: 13145-1384, Tehran, Iran \\ Department of Biochemistry, Faculty of Science, Tarbiat Modarres University, Tehran, Iran
}

Received 6 January 2004, Accepted 9 March 2004

\begin{abstract}
The lysine residues of Bacillus licheniformis $\alpha$-amylase (BLA) were chemically modified using citraconic anhydride or succinic anhydride. Modification caused fundamental changes in the enzymes specificity, as indicated by a dramatic increase in maltosidase and a reduction in amylase activity. These changes in substrate specificity were found to coincide with a change in the cleavage pattern of the substrates and with a conversion of the native endo- form of the enzyme to a modified exo- form. Progressive increases in the productions of $\rho$-nitrophenol or glucose, when para nitrophenyl-maltoheptaoside or soluble starch, respectively, was used as substrate, were observed upon modification. The described changes were affected by the size of incorporated modified reagent: citraconic anhydride was more effective than succinic anhydride. Reasons for the observed changes are discussed and reasons for the effectivenesses of chemical modifications for tailoring enzyme specificities are suggested.
\end{abstract}

Keywords: Bacillus licheniformis $\alpha$-amylase, Chemical modification, Citraconic anhydride, Substrate specificity, Succinic anhydride

\section{Introduction}

The chemical modification of enzymes provides us with a means of elucidating enzymatic properties. Originally, this approach was used to identify specific residues at active sites

${ }^{\S}$ Present address: Stanford Genome Technology Center, Stanford University, 855 California Ave., Palo Alto, CA 94304, USA, Tel: 1-650 812 1961; Fax: 1-650 812 1975; E-mail: mohsenn@stanford.edu

*To whom correspondence should be addressed.

Tel: 98-21-6113377; Fax: 98-21-6404680

E-mail: gorganim@ibb.ut.ac.ir involved in substrate binding or chemical catalysis. More recently, however, it has been used for tailoring the specificities of enzymes, including $\alpha$-amylases (Kaiser et al., 1985; Yamashita et al., 1993; Qi et al., 2001; Davis, 2003). Due to the conserved nature of residues around the active sites of $\alpha$-amylases, and the close similarities between their threedimensional structures (Machius et al., 1995; MacGregor et $a l ., 2001)$, the results obtained provide information of general utility for various $\alpha$-amylases including those with unusual mechanism of action (Ammar et al., 2002). The creation of enzymes with new catalytic activities, and the tailoring of the specificities of existing enzymes to accommodate unnatural substrates, is currently an area of intense research.

The $\alpha$-amylase of Bacillus licheniformis (BLA) is a highly thermostable enzyme and a member of the endoamylases (E.C 3.2.1.1), which catalyze the cleavage of $\alpha$-D $(1 \rightarrow 4)$ glycosidic bonds in starch and related carbohydrates, and which have several industrial applications. In a previous communication, the chemical modification of lysine residues in this enzyme was shown to result in some profound changes in its kinetic parameters (Khajeh et al., 2001a). In this report, further studies are presented which describe changes in the substrate specificity of this enzyme after modification of the $\varepsilon$ amino groups of its lysine residues.

\section{Material and Methods}

Thermostable $\alpha$-amylase from $B$. licheniformis (BLA), mesophilic $\alpha$-amylase from $B$. amyloliquefaciens (BAA), $\alpha$-glucosidase, glucose oxidase, citraconic anhydride, succinic anhydride, para nitrophenyl- $\alpha$-D-maltopentaoside ( $\rho N P$-maltopentaoside), and para nitrophenyl- $\alpha$-D-maltoside $\left(\mathrm{G}_{2} \rho \mathrm{NP}\right)$ were purchased from Sigma (St. Louis, USA). Ethylidene para nitrophenyl- $\alpha-\mathrm{D}-$ maltoheptaoside (EPS) was from Roche (Mannheim, Germany) and all other chemicals were obtained from Merck (Darmstadt, Germany). The reproducibility of the data presented in this manuscript was confirmed by repeating all experiments at least twice. 
Determination of enzymatic activity and protein concentration To determine maltosidase activity, $\alpha$-amylase $(6 \mu \mathrm{g} / \mathrm{ml})$ was assayed at $37^{\circ} \mathrm{C}$, using EPS $(2 \mathrm{mM}$ with or without $\alpha$-glucosidase $)$ or para nitrophenyl- $\alpha$-D-maltopentaoside $(3 \mathrm{mM})$ as substrate at $\mathrm{pH}$ 7.5 in $20 \mathrm{mM}$ Tris. These procedures are based on the progressive hydrolysis of the substrate, and the gradual release of para nitrophenol, which shows an absorption maximum at $405 \mathrm{~nm}$ (Hägele et al., 1982). The initial rate corresponding to the first $120 \mathrm{~s}$ was taken to represent enzymatic activity. The amylase activity ( $3 \mu \mathrm{g} / \mathrm{ml}$ of the enzyme) was determined at $37^{\circ} \mathrm{C}$, using $1 \%$ soluble starch as substrate at $\mathrm{pH} 7.5$ in $20 \mathrm{mM}$ Tris. The Bernfeld method was used to determine reducing sugar levels (Bernfeld, 1955).

The release of glucose was assessed in the usual manner, by allowing the enzyme to react with starch for $24 \mathrm{~h}$. The reaction was then stopped with $2 \mathrm{M} \mathrm{NaOH}$ and the amount of glucose in the medium was assayed using glucose oxidase (Farrance, 1987). Protein concentrations were determined using the pyrogallol red method (Watanabe, 1986).

Modification of lysine residues Lysine was modified using citraconic anhydride and succinic anhydride as specific blocking agents for lysine residues, by following the procedure described by Dixon and Perham (Dixon and Perham, 1968). Protein was used at $4 \mathrm{mg} / \mathrm{ml}$ in $10 \mathrm{ml}$ of $100 \mathrm{mM}$ borate ( $\mathrm{pH} 8.0$ ) and the process was followed at room temperature by the step-wise addition of $3 \mu \mathrm{l}$ aliquots of citraconic anhydride, as described previously (Khajeh $e t$ al., 2001a) or by the step-wise addition of $4 \mathrm{mg}$ amounts of succinic anhydride $(4,8,16$ and $22 \mathrm{mg}$ ), while maintaining the $\mathrm{pH}$ of the stirred solution at 8.0 by adding $2 \mathrm{M} \mathrm{NaOH}$. After each reagent addition, and after ensuring a constant $\mathrm{pH}$, a sample was removed from the solution and kept on ice. All samples were then dialyzed extensively against $20 \mathrm{mM}$ Tris, $\mathrm{pH}$ 7.5. To determine the number of modified lysine residues, the number of free amino groups in the protein was measured, using the method described by Fields (Fields, 1971). Briefly, samples were first dialyzed in $0.1 \mathrm{M}$ borate buffer ( $\mathrm{pH} 9.5$ ), and the final protein concentration was then adjusted to $0.7 \mathrm{mg} / \mathrm{ml}$. Succinylation resulted in the modification of $5,6,12$, and 16 residues, and citraconylation in the modification of $5,10,13$, and 16 residues, out of a total number of 27 lysine residues in BLA. To assess the surface accessibility of the lysine residues in BLA (pdb1bli), we used MOLMOL version 2K.2.

\section{Results and Discussion}

The design and production of new enzymes with high preferences for specific substrates constitutes an important area of present-day protein engineering. Included in this endeavor is the creation of enzymes capable of the site-specific cleavage of large substrates. Studies on some well-characterized enzymes, including $\alpha$-amylases, have shown that substrate specificities can be tailored chemically by modifying or mutating amino acid residues to which substrates bind (Matsui, 1992; Alcalde $e t$ al., 1999). Compared with the limitations imposed by the restricted number of proteinogenic amino acids, the use of chemical modification, although generally non-specific in nature, allows a virtually unlimited means of altering the amino

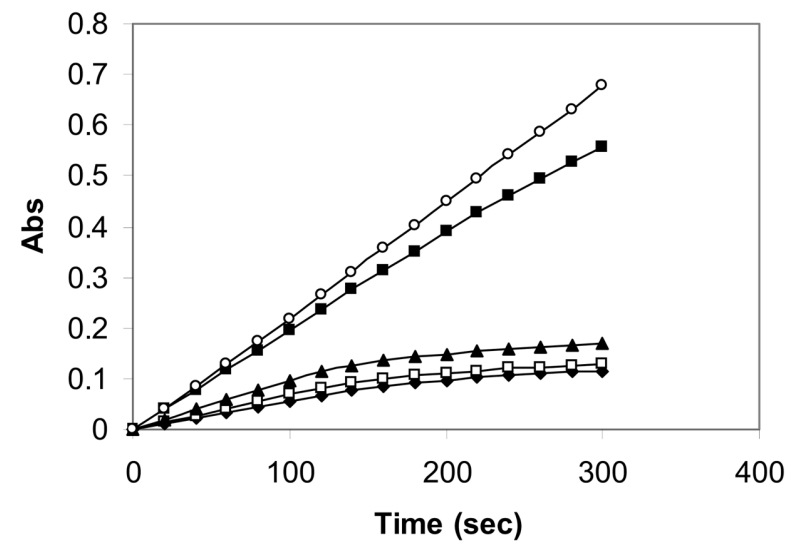

Fig. 1. Comparison of native and citraconic anhydride-modified enzymes, with respect to their activities toward $\rho N P$ maltoheptaoside (in the absence of $\alpha$-glucosidase). Absorbance at $405 \mathrm{~nm}$ was monitored against time (seconds). Native $(\diamond), 5-$ lysine-modified ( $\square$ ), 10-lysine-modified ( $\boldsymbol{\Delta}$ ), 13-lysine-modified $(\boldsymbol{\square})$, and 16-lysine-modified enzyme $(\bigcirc)$.

acid side chain structures of proteins. With the advent of novel procedures that exploit selective and efficient protein chemistry, this strategy, either alone or in combination with site-directed mutagenesis, could make a significant contribution to this area of biotechnology. In a recent communication, we reported on substantial alterations in the kinetic parameters of BLA produced by modifying its lysine residues with citraconic anhydride (Khajeh et al., 2001b). Here, we outline further details of the marked changes these modifications have on the catalytic behaviors of such enzymes.

The relationship between increased absorbance with time, related to the hydrolysis of EPS is illustrated in Fig. 1. As indicated, the catalytic potential of BLA is dramatically enhanced by modification. Also, as the number of modified residues increases, the initial higher rate of absorbance increase is prolonged, so that in the case of the 16-modified residue enzyme, a constant increase in absorbance was observed during the entire assay period (300 seconds).

The following scheme has been proposed in relation to the enhanced maltosidase activity observed after modifying lysine residues in porcine pancreatic $\alpha$-amylase (Yamashita et al., 1993):

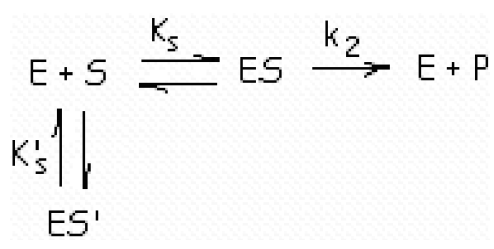

Scheme 1.

where $E$ represents the native or modified enzyme, $S$ and $P$ the substrate and products, ES the productive enzyme-substrate complex, ES' the non-productive enzyme-substrate complex, 
$\mathrm{K}_{\mathrm{S}}$ and $\mathrm{K}_{\mathrm{S}}^{\prime}$ the dissociation constants of the productive and non-productive enzyme-substrate complexes, and $\mathrm{k}_{2}$ the first order rate constant of the product formation step.

Based on the cleavage pattern of a $\mathrm{NNP}$-maltoheptaoside, recently published for BLA (Kandra et al., 2002, and Fig. 2), and reports in the literature related to the maltosidase activities of various $\alpha$-amylases, the production of $G_{2} \rho N P$ and $G_{3} \rho N P$ in addition to $\rho N P$ release is suggested. Furthermore, we propose that these $\rho N P$ derivatives bind the enzyme in a nonproductive manner, which is in-line with the limited absorbance increase obtained using the native enzyme (Fig. 1). Moreover, the modified BLA is presumed to be converted to a new exo-type enzyme capable of hydrolyzing the bond between the $\rho$-nitrophenyl group and the remainder of the substrate (Fig. 3), as has been observed for other $\alpha$-amylases after modification (Kita et al., 1982; Ishikawa and Hirata, 1989; Yamashita et al., 1991; Kobayashi et al., 1992; Yamashita et al., 1993; Nakatani et al., 1994). This mechanism would explain the high rate of absorbance increase, versus the limited absorbance increase achieved using the native enzyme (Fig. 1). The suggested change in the pattern of cleavage is in line with the conversion of the non-productive mode of catalysis to a productive one, as described above, and this was further confirmed by using $\alpha$-glucosidase. The addition of this exo-type enzyme to the assay medium, either at the onset or at the mid-point of the assay (see Fig. 1) increased absorbance to an extent similar to the one achieved using the modified enzyme (results not shown).

The active site of all enzymes belonging to the $\alpha$-amylase family is considered to be composed of a number of subsites, each of which is capable of interacting with a glucose residue of the substrate (MacGregor, 2001). The subsites themselves are composed of side chains of amino acid residues situated on loops in the enzyme structure that connect the C-terminal ends of the $\beta$-strands to the $\mathrm{N}$-terminal ends of the adjacent helices of the $(\beta / \alpha)_{8}$-barrel of the catalytic domain. The subsite structures of $\alpha$-amylases, such as of TAKA amylase (Brzozowski and Davies, 1997) and of porcine pancreatic alpha amylase (Qian et al., 1997) have been described in the literature. However, detailed knowledge about the subsite architecture of BLA is scarce and information on the kinetics and mode of action of this industrially-important enzyme is limited in the literature. It has been suggested that the active site of this enzyme consists of eight subsites, and that the catalytic site is located between subsites 5 and $6(-1 \rightarrow+1)$. Moreover, a "barrier" subsite has also been proposed to exist in the binding region of this enzyme (Kandra et al., 2002). Accordingly, it has been suggested that the cleavage of $\rho \mathrm{NP}$ at the catalytic site between subsites 5 and 6 occurs when the substrate is placed at the active site of the modified enzyme with the terminal glucose- $\rho$ NP located at this position (Fig. 3), as directed by the modified substrate recognition mechanism. It is assumed that additional hydrogen bonding opportunities, together with possible hindrance in freedom of movement of the substrate contribute toward the fitting and fixing of the terminal glucose or $\rho \mathrm{NP}$ at this location.

Additional data in support of the fundamental alteration of the substrate specificity of BLA by chemical modification is provided by its amylase activity. As indicated in Table 1, the amylase activity of the modified enzyme progressively

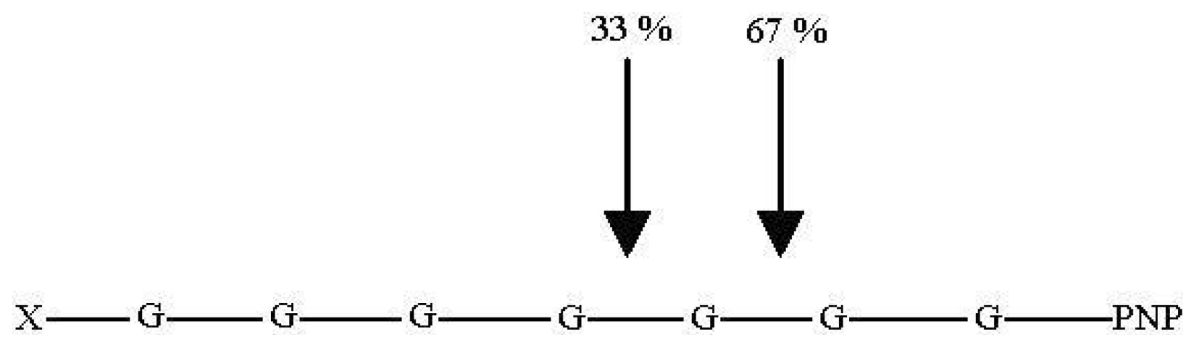

Fig. 2. Scheme of the mode of action of BLA on $\rho$ NP-maltoheptaoside as substrate. Numbers above the arrows represent glycosidic bond cleavage frequencies (\%). (From Kandra et al., 2002).

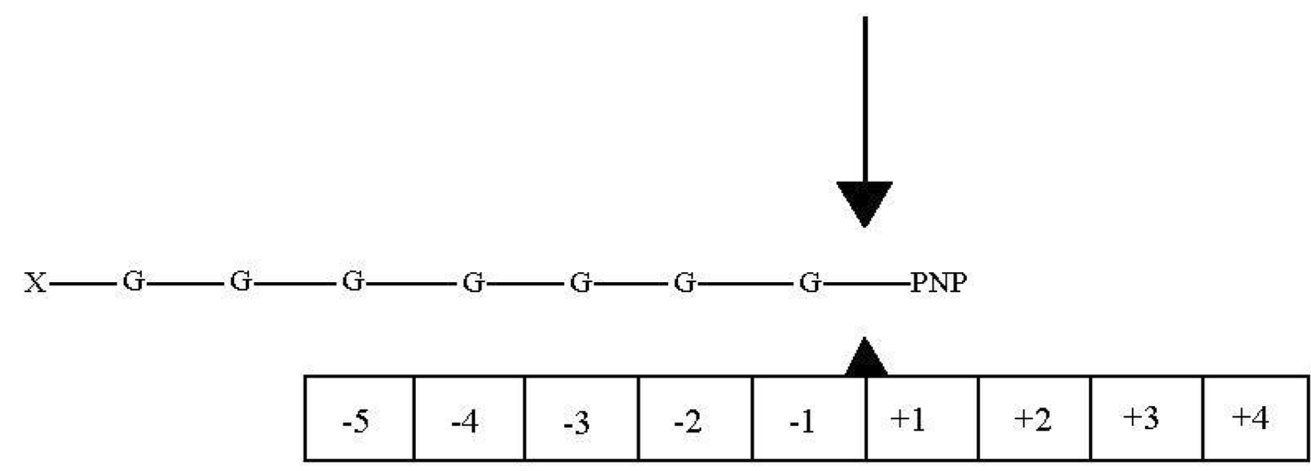

Fig. 3. Suggested mode of action of the modified enzyme on EPS. The numbers indicated represent subsites at the active site. 
Table 1. Maltosidase-amylase activities and the production of glucose by native $\alpha$-amylase (BLA) and the enzyme modified with citraconic anhydride

\begin{tabular}{cccc}
\hline Sample & $\begin{array}{c}\text { Maltosidase activity } \\
\text { ratios (modified/native) }\end{array}$ & $\begin{array}{c}\text { Amylase activity } \\
\text { ratios (modified/native) }\end{array}$ & $\begin{array}{c}\text { Glucose production } \\
\text { ratios (modified/native) }\end{array}$ \\
\hline BLA control & 1.00 & 1.00 & 1.00 \\
BLA 5 mod. & 1.19 & 1.06 & 0.95 \\
BLA 10 mod. & 1.66 & 0.90 & 0.89 \\
BLA 13 mod. & 3.47 & 0.33 & 2.52 \\
BLA 16 mod. & 3.88 & 0.12 & 9.5 \\
\hline
\end{tabular}

Enzymatic activities and glucose production were determined as described in Materials and Methods. The data presented are activity/ glucose production ratios for native and modified enzyme.

reduced as glucose production was concomitantly and substantially increased.

These data, taken together, support fundamental changes in the substrate specificity of the enzyme (i.e., in its maltosidase and amylase activities), as discussed above.

Modification of $\varepsilon$-amino groups of lysine residues (scheme 2 ), at the active site of the enzyme would result in the provision of bulky groups and present new hydrogen bonding opportunities involving the glucose moieties of the substrate.<smiles>CCC[As](CC)NC(=O)/C(C)=C\C(=O)O</smiles><smiles>CCC[As](CC)NC(=O)/C=C(/C)C(=O)O</smiles>

Scheme 2.

Indeed, an abnormally high pKa has been reported for the carboxylic group of the modified lysine residue (Khajeh et al., 2001a), which reflects a negatively charged environment, such as that caused by the location of acidic residues at the active site. It should be pointed out that two aspartic acid and one glutamic acid residues constitute three conserved catalytic residues at the active site of all $\alpha$-amylases, a family of enzymes with a similar mode of action (MacGregor et al., 2001). A portion of the active site of BLA, which includes these three amino acids and lysine 234 (a residue possibly modified in the present study), is depicted in Fig. 4. This representation is based on information provided by Machius et al (Machius et al.,1998). The numbers in parentheses indicate the corresponding subsites in the enzyme. Another residue, which may also be modified is lysine 237 , located in the vicinity of lysine 234 (Fig. 4) and with a surface accessibility of $11 \%$; somewhat higher than that estimated for lysine 234 (6.7\%). Lysine 237 has already been proposed as a possible candidate in a study involving the modification of BLA by citraconic anhydride (Khajeh et al., 2001 b).

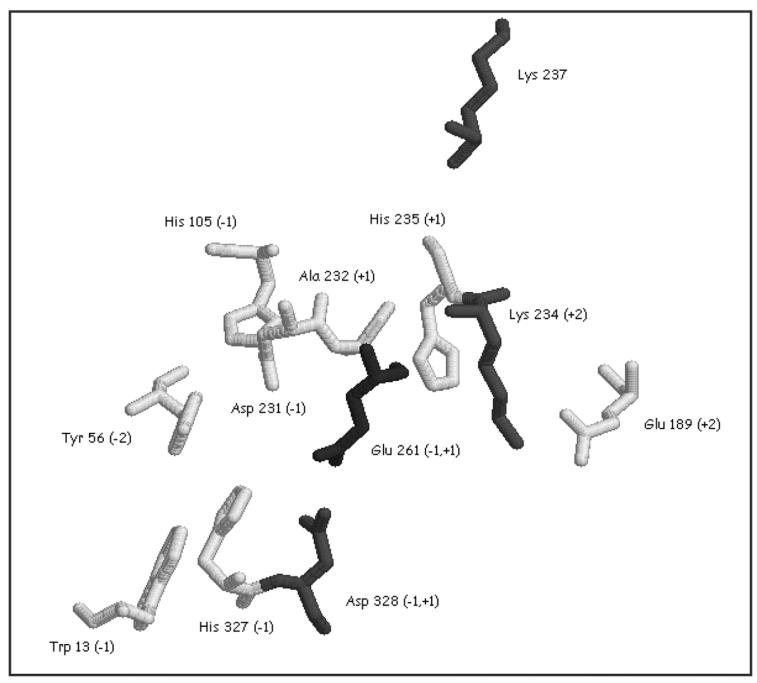

Fig. 4. Amino acid residues of BLA active site (pdb1bli). The figure was drawn using RasMol version 2.7.1. Subsites are numbered according to Machius et al., 1998. For more details refer to the text.

Another piece of evidence supporting the suggested reasons for the described changes in activity of the modified enzyme is provided by the data obtained using succinic anhydride, a less bulky, but an otherwise similar modifier. All changes indicated in Table 1 were also observed for the enzyme modified with this reagent, but to a lesser extent (Table 2). This is in line with suggestions made in the literature on the importance of the volume of incorporated modification reagent with respect to observed increased maltosidase activities of $\alpha$-amylases (Yamashita et al., 1993). The higher amylase activities indicated in Table 2 (together with the lower production of glucose) suggest a less hindered approach to the active site by starch molecules, provided by a less bulky modified lysine residue. This situation was not encountered when BAA was modified by citraconic anhydride (Table 3), which may be due to this enzyme having a more extended/ bulky active site than BLA (Kandra et al., 2002). Therefore, it appears that subtle differences in the modification of residues at the active site may significantly affect substrate specificity. 
Table 2. Maltosidase-amylase activities and the production of glucose by native $\alpha$-amylase (BLA) and the enzyme modified with succinic anhydride

\begin{tabular}{cccc}
\hline Sample & $\begin{array}{c}\text { Maltosidase activity } \\
\text { ratios (modified/native) }\end{array}$ & $\begin{array}{c}\text { Amylase activity } \\
\text { ratios (modified/native) }\end{array}$ & $\begin{array}{c}\text { Glucose production } \\
\text { ratios (modified/native) }\end{array}$ \\
\hline BLA control & 1.00 & 1.00 & 1.00 \\
BLA 5 mod. & 1.18 & 0.91 & 1.06 \\
BLA 6 mod. & 1.21 & 0.86 & 0.98 \\
BLA 12 mod. & 1.72 & 0.80 & 1.21 \\
BLA 16 mod. & 2.05 & 0.72 & 1.54 \\
\hline
\end{tabular}

Details as described for Table 1.

Table 3. Maltosidase-amylase activities and glucose production for native $\alpha$-amylase (BAA) and the enzyme modified with citraconic anhydride

\begin{tabular}{cccc}
\hline Sample & $\begin{array}{c}\text { Maltosidase activity } \\
\text { ratios (modified/native) }\end{array}$ & $\begin{array}{c}\text { Amylase activity } \\
\text { ratios (modified/native) }\end{array}$ & $\begin{array}{c}\text { Glucose production } \\
\text { ratios (modified/native) }\end{array}$ \\
\hline BAA control & 1.00 & 1.00 & 1.00 \\
BAA 15 mod. & 1.18 & 0.64 & 1.09 \\
BAA 20 mod. & 0.93 & 0.23 & 1.45 \\
\hline
\end{tabular}

Details are as described for Table 1.

Maltosidase activity was also increased by modifying BLA with the two modifiers (citraconic anhydride and succinic anhydride) and by using $\rho N P$-maltopentaoside as a substrate instead of EPS. However, the size of the modifier was not as important as in the case of EPS, presumably due to a smaller size of the former substrate.

An enhancement of maltosidase activity combined with a reduction in amylase activity have been reported for lysine (Kobayashi et al., 1992; Yamashita et al., 1993) or histidine (Kita et al., 1982; Ishikawa and Hirata, 1989; Yamashita et al., 1991; Nakatani et al., 1994) residue modifications, of a number of $\alpha$-amylases. Several reasons have been put forward to explain these observations; changes in the degree of nonproductive binding (Ishikawa and Hirata, 1989; Yamashita et al., 1993), conformation of the active site (Ishikawa and Hirata, 1989, Yamashita et al., 1991), stabilization of the transition state during catalysis (Nakatani et al., 1994), a better interaction between the $\rho \mathrm{NP}$ moiety of the substrate and the introduced group (Yamashita et al., 1993; Yamashita et al., 1995). Another important finding in these studies is the possibility of selective substrate inhibition induced by modification (Nakatani,1988; Ishikawa and Hirata, 1989).

\section{Conclusions}

The results presented indicate that the substrate specificity of BLA is changed fundamentally by the chemical modification of its lysine residues. Furthermore, they demonstrate the effectiveness of chemical modification for tailoring enzyme specificity and for providing additional tests for the validity of generally-accepted concepts related to the chemical basis of enzyme specificity.

Acknowledgments Financial support for this work was provided by the Research Council, University of Tehran.

\section{References}

Alcalde, M., Plou, F. J., Andersen, C., Martin, M. T., Pedersen, S. and Ballesteros, A. (1999) Chemical modification of lysine side chains of cyclodextrin glycosyltransferase from Thermoanaerobacter causes a shift from cyclodextrin glycosyltransferase to -amylase specificity. FEBS Lett. 445, 333-337.

Ammar, Y. B., Matsubara, T., Ito, K., Iizuka, M., Limpaseni, T., Pongsawasadi, P. and Minamura, N. (2002) New action pattern of a maltose-forming $\alpha$-amylase from Streptomyces sp. and its possible application in bakery. J. Biochem. Mol. Biol. 35, 568575.

Bernfeld, P. (1955) $\alpha$-and $\beta$-amylases; in Methods in Enzymology, Colowick, S. P. and Kaplan, N. (eds.), pp. 149-154, Academic Press, New York, USA.

Brzozowski, A. M. and Davies, G. J. (1997) Structure of the Aspergillus oryzae alpha-amylase complexed with the inhibitor acarbose at 2.0 A resolution. Biochemistry 36,10837-10845.

Davis, B. G. (2003) Chemical modification of biocatalysts. Curr. Opin. Biotechnol. 14, 379-386.

Dixon, H. B. F. and Perham, R. N. (1968) Reversible blocking of amino groups with citraconic anhydride. Biochem. J. 109, 312314.

Farrance, I. (1987) Plasma glucose methods, a review. Clin. Biochem. Rev. 8, 55.

Fields, R. (1971) The measurement of amino groups in proteins and peptides. Biochem. J. 124, 581-590.

Hägele, E. O., Schaich, E., Rauscher, E., Lehmann, P., Burk, H. 
and Wahlefeld, A. W. (1982) Mechanism of action of human pancreatic and salivary alpha-amylase on alpha-4-nitrophenyl maltoheptaoside substrate. Clin. Chem. 28, 2201-2205.

Ishikawa, K. and Hirata, H. (1989) New substrate specificity of modified porcine pancreatic alpha-amylase. Arch. Biochem. Biophys. 272, 356-363.

Kaiser, E. T., Lawrence, D. S. and Rokita, S. E. (1985) The chemical modification of enzymatic specificity. Annu. Rev. Biochem. 54, 565-595.

Kandra, L., Gyémánt, G., Remenyik, J., Hovánszki, G. and Lipták, A. (2002) Action pattern and subsite mapping of Bacillus licheniformis alpha-amylase (BLA) with modified maltooligosaccharide substrates. FEBS Lett. 518, 79-82.

Khajeh, K., Naderi-Manesh, H., Ranjbar, B., Moosavi-Movahedi, A. A. and Nemat-Gorgani, M. (2001a) Chemical modification of lysine residues in Bacillus alpha-amylases: effect on activity and stability. Enzyme Microb. Technol. 28, 543-549.

Khajeh, K., Ranjbar, B., Naderi-Manesh, H., Ebrahim Habibi, A. and Nemat-Gorgani, M. (2001b) Chemical modification of bacterial alpha-amylases: changes in tertiary structures and the effect of additional calcium. Biochim Biophys Acta. 1548, 229237.

Kita, Y., Sakaguchi, S., Nitta, Y. and Watanabe, T. (1982) Kinetic study on chemical modification of Taka-amylase A. II. Ethoxycarbonylation of histidine residues. J. Biochem. 92, 1499-1504.

Kobayashi, M., Miura, M. and Ichishima, E. (1992) Modification of subsite Lys residue induced a large increase in maltosidase activity of Taka-amylase A. Biochem. Biophys. Res. Commun. 183, 321-326.

MacGregor, E. A., Janeèek, Š. and Svensson, B. (2001) Relationship of sequence and structure to specificity in the alpha-amylase family of enzymes. Biochim. Biophys. Acta 1546, 1-20.

Machius, M., Wiegand, G. and Huber, R. (1995) Crystal structure of calcium-depleted Bacillus licheniformis alpha-amylase at 2.2 Å resolution. J. Mol. Biol. 246, 545-559.
Machius, M., Declerck, N., Huber, R. and Wiegand, G. (1998) Activation of Bacillus licheniformis alpha-amylase through a disorder-->order transition of the substrate-binding site mediated by a calcium-sodium-calcium metal triad. Structure. 6, 281-292.

Matsui, I., Ishikawa, K., Miyairi,S., Fukui, S. and Honda, K. (1992) A mutant alpha-amylase with enhanced activity specific for short substrates. FEBS Lett. 310, 216-218.

Nakatani, H. (1988) Selective inhibition of histidine-modified pancreatic alpha-amylase by proteinaceous inhibitor from Phaseolus vulgaris. Arch. Biochem. Biophys. 263, 364-368.

Nakatani, H., Hamaguchi, K. and Ishikawa, K. (1994) Effect of modifying histidine residues on the action of Bacillus amyloliquefaciens and barley-malt alpha-amylases. Carbohydr. Res. 257, 155-161.

Qi, D., Tann, C-M., Haring, D. and Distefano, M. D. (2001) Generation of new enzymes via covalent modification of existing proteins. Chem. Rev. 101, 3081-3111.

Qian, M., Spinelli, S., Drigez, H. and Payan, F. (1997) Structure of a pancreatic alpha-amylase bound to a substrate analogue at 2.03 Å resolution. Protein Sci. 6, 2285-2296.

Watanabe, N., Kamei, S., Ohkubo, A., Yamanaka, M., Ohsawa, S., Makino, K. and Tokuda, K. (1986) Urinary protein as measured with a pyrogallol red-molybdate complex, manually and in a Hitachi 726 automated analyzer. Clin. Chem. 32, 1551-1554.

Yamashita, H., Nakatani, H. and Tonomura, B. (1991) Substrateselective activation of histidine-modified porcine pancreatic alpha-amylase by chloride ion. J. Biochem. 110, 605-607.

Yamashita, H., Nakatani, H. and Tonomura, B. (1993) Change of substrate specificity by chemical modification of lysine residues of porcine pancreatic alpha-amylase. Biochim. Biophys. Acta 1202, 129-134.

Yamashita, H., Nakatani, H. and Tonomura, B. (1995) Effect of a p-nitro group of phenyl-maltooligosaccharide substrate on the change of action specificity of lysine-modified porcine pancreatic alpha-amylase. Biochem. Mol. Biol. Int. 35, 79-85. 